
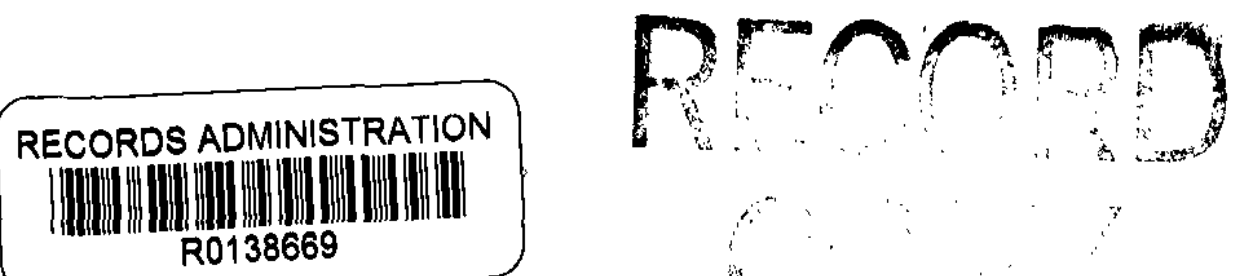

Instrumentation

38669

\begin{tabular}{c} 
DO VERSATILE LABORATORY \\
SERVO - AMPLIFIER \\
by \\
L. M. Johnson \\
Instrument Development Division \\
March 1955 \\
\hline
\end{tabular}

E. I. du Pont de Nemours \& Co.

Explosives Department - Atomic Energy Division Technical Division - Savannah River Laboratory 


\section{A VERSATILE LABORATORY SERVO-AMPLIFIER}

by

L. M. Johnson

Instrument Development Division

March 1955

E. I. du Pont de Nemours \& Co. Explosives Department - Atomic Energy Division Technical Division - Savannah River Laboratory

Printed for

The United States Atomic Energy Commission Contract $\operatorname{AT}(07-2)-1$ 


\section{INTERNAL DISTRIBUTION}

No. of Copies

(5) AEC, SROO

(I) R. M. Evans -

B. H. Mackey

(I) J. E. Cole - M. H. Smith J. B. Tinker

(1) W. C. Kay - H. Worthington

(1) D. F. Babcock

(I) S. I. Winde

(1) J. D. Ellett

(1). W. P. Overbeck

(1) T. C. Evans

(1) J. D. Cist

1) H. J. Bowman - W. M. SIoan

I) W. S. Church

I) A. A. Johnson

I) P. S. Shane

(1) M. M. Mann

(1) R.H. Dietz

(1) PRD File

(I) M. H. Wahl -

C. W. J. Wende

(I) J. W. Croach -

L. M. Arnett

(1) J. N. Wilson

(1) L. Cathey

(1) L. M. Johnson

(15) TIS File

(1) TIS File Record Copy
Augusta, Ga.

Wilmington AED

$"$

Engineering Department

Savannah River Plant

"

19

II

II

11

11

II

"

II

Savannah River Laboratory
11
II
II
II
II
11 
EX-1176-Ax
ब1UPOND
E. I. DU PONT DE NEMOURS \& COMPANY
INCORPORATED
Savannah River plant
AIKen, SOUTH Carolina
(TEL. \& TEL. ADDRESS, AUGUSTA, GA.)

t

EXPLOSIVES DEPARTMENT

ATOMIC ENERGY DIVISION

June 27,1956

To: Recipients of DP-112, "A Versatile Laboratory ServoAmplifier", by L. M. Johnson.

\section{CORRECTION NOTICE}

The gain of the servo-amplifier described in the subject report has been determined to be higher than was originally reported. This higher gain is sufficient to cause the amplifier to develop a regenerative feeaback resulting in oscillation. Subsequent modification of the amplifier has eliminated this feedback, and the report should be corrected according to the attached diagram.

The driver stage should be converted to a push-pull cathode follower by deleting R25, R26, and R27 and then adding resistors $J$ and $K$ as shown. This conversion reduces the overall gain, as the gain of a cathode follower is always less than unity.

The original diagram shows $R 9, R 33$, and $R 34$ disconnected from $\mathrm{B}^{-}$. This connection should be made as shown. Coupling capacitor $\mathrm{C} 9$ is identical to $\mathrm{C} 8$ instead of $25 \mathrm{mfd}$ as listed on page 10.

In the event that the G. E. transformer listed for T3 is not obtainable, a Stancor A-8103 is an excellent substitute.

TECHNICAL DIVISION

SAVANNAH RIVER LABORATORY

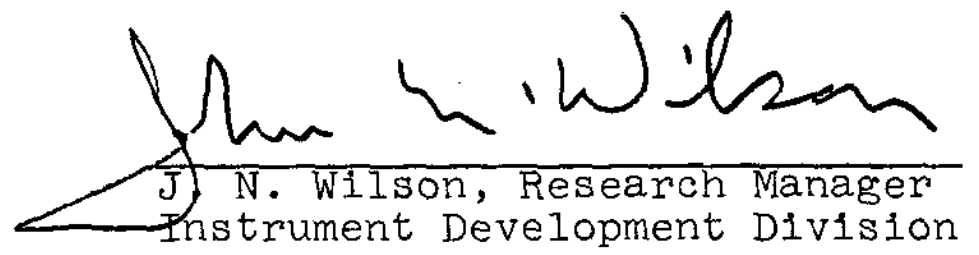

WJW/eef 


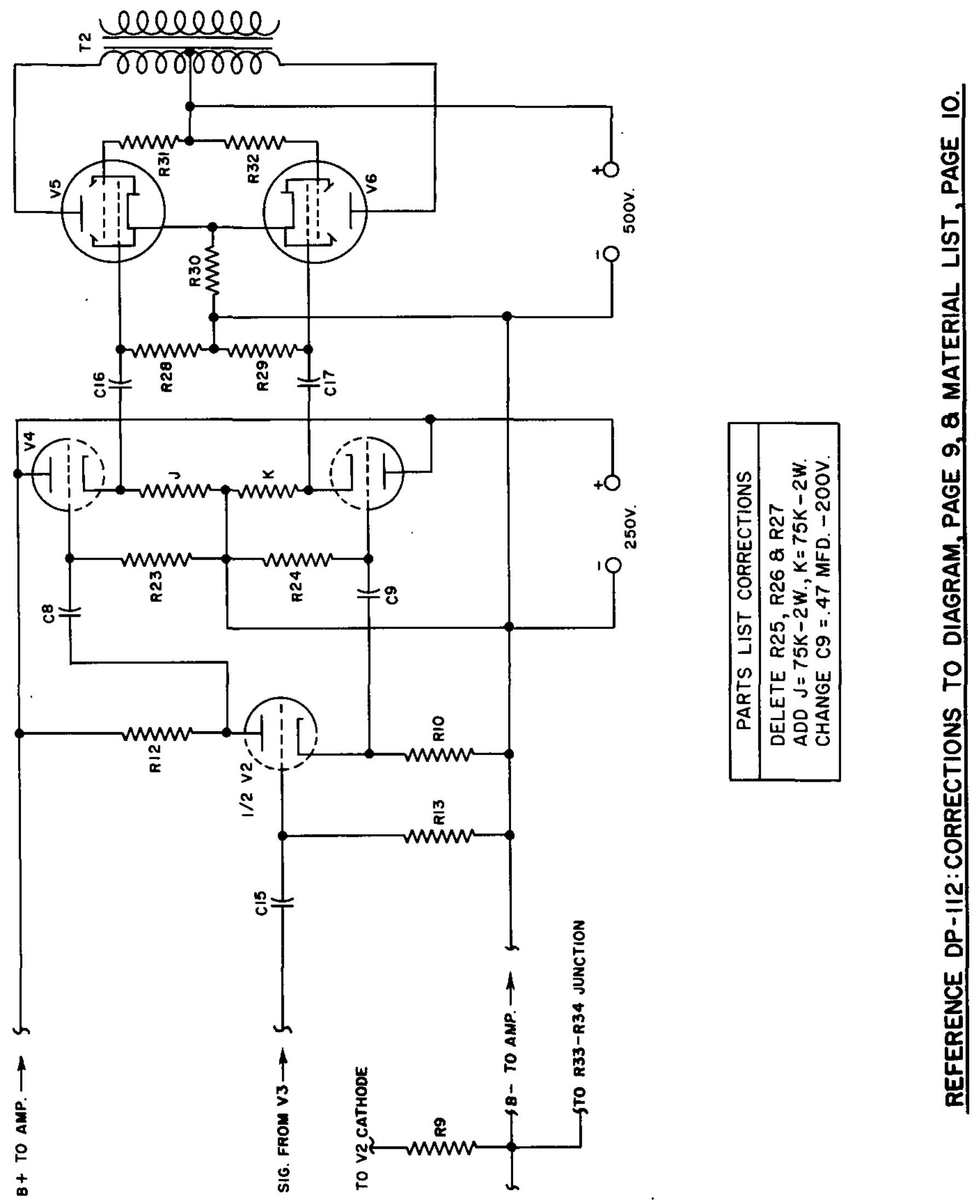


DP - 112

ABSTRACT

A versatile amplifier was developed for use as a laboratory instrument in the design of various electrical servo systems.

External Distribution according to TID-4500, 9th Edition. 
Figure 1. Photograph, Front Pane1......... 8 Figure 2. Circuit Diagram of Amplifier . . . . . 9 Figure 3. Photograph, Rear of Chassis....... 11 


\section{A VERSATILE LABORATORY SERVO-AMPLIFIER}

\section{INTRODUCTION}

Control and remote manipulation systems often involve electrical servo systems which require various types of amplifiers. Since commercial amplifiers are usually packaged units that are difficult to adjust and modify, a need existed for a general-purpose servo-amplifier which had variable characteristics and could be modified with a minimum of effort. This report covers the development of such an amplifier.

\section{SUMMARY}

A flexible servo-amplifier was developed with the following characteristics:

A. The servo-amplifier employs a carrier frequency of $60 \mathrm{cps}$,

B. The amplifier will accept either AC or DC signals and has a maximum gain of $10^{6}$ with microvolt signals, or $10^{3}$ with millivolt signals. The input impedance is 250,000 ohms.

C. The error signal may be limited internally to any preset level. The variable feedback may be obtained internally or externally. The carrier phase may be shifted through 150 degrees. 
$\mathrm{DP}-112$

Page 5

\section{DISCUSSION}

The servo motors most used in SRL control systems are two-phase AC (60 cps) control motors requiring a rated voltage input of 115 volts and a power input of 5 to 20 watts. Error detectors or transducers may supply either an AC or a DC signal. The amplifier designed to be used with these components is shown in Figure 2 .

INPUT CIRCUIT

The amplifier accepts either AC or DC signals; the proper input terminals (Figures 1 and 2) are connected into the circuit by the AC/DC switch (SW 1). The AC is fed directly to the first amplifier stage while the DC is fed to a $60 \mathrm{cps}$ chopper before going to the first stage. The $\mu \mathrm{v} / \mathrm{mv}$ switch (SW 2) selects the proper input for signals in the upper microvolt or millivglt range. The maximum gain with the microvolt input is $10^{6}$ and that with the millivolt input is 1000. The input impedance for both ranges is approximately 250,000 ohms. A continuous variation in gain on either range is obtained by the gain control potentiometer, $R_{7}$.

CARRIER AND SIGNAL CONTROL

A limiter circuit, which is connected to the input of the third amplifier stage, prevents the error signal from exceeding a preset level. The limiting action is accomplished by biasing a pair of diodes to the preset level; signals above that level are conducted to ground. The limiter is switched out of the circuit by Switch 3 (Figures 1 and 2 ).

A stabilizing and damping characteristic is supplied by a potentiometer, $R_{16}$, which is connected to the output of the third amplifier stage and feeds back part of the output voltage to the cathode of the same stage. The amount of feedback is selected by setting the knob on the front panel. Input terminals for resistive and tachometric feedback (not presently used in the circuit) are located on the front panel.

Also connected to the output of the third stage is a phase shifting circuit. By varying potentiometer $R_{13}$; the 60 cps carrier phase may be shifted a total of 150 degrees.

OUTPUT CIRCUIT

The push-pull output. stage is connected directly to the primary of the output transformer. The twelve secondary leads from the transformer are connected to banana jacks at one side of the amplifier chassis (Figure 3). Various output impedances are easily obtained by selecting different output windings according to the following table: 
output

Impedance Ohms

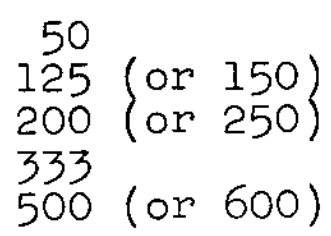

Connect

To

8 and 10

7 and 10

8 and 1.1

7 and 11

7 and 12
Join

Together

8 and 9,10 and 11

7 and 9,10 and 12

9 and 10

9 and 10

9 and 10

The power output leads (Figure 3) are connected to banana jacks on the front panel (Figure 1) providing a convenient outlet for the motor power. Voltage and current supplied to the motor are read directly from the voltmeter and ammeter on the front panel. (Figure 1).

\section{POWER REQUIREMENTS}

The servo-amplifier is designed for use with laboratory power supplies such as the Hewlett-Packard Model $712 \mathrm{~A}$ or the Sorenson Model 500BB. The power requirements are: 6.3 volts $A C$ at 4 amps; 250 volts DC at $70 \mathrm{ma}$; and 360 volts $\mathrm{DC}$ at $120 \mathrm{ma}$. Power is supplied to the rear of the amplifier chassis through banana jacks, as shown in Figure 3 .

GENERAL

To facilitate changes and additions in the circuitry, a11. the resistors and capacitors are mounted on two resistor poards, which are placed back-to-back and are mounted in the center of the underside of the chassis. The resistors and capacitors are numbered as indicated on the circuit diagram for easy identification.

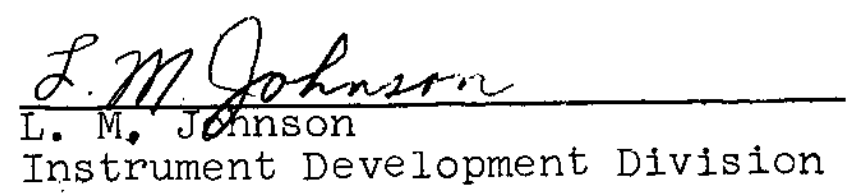


DP - 112

Page 7

\section{BIBLIOGRAPHY}

1. Eastman, A. V. Fundamentals of Vacuum Tubes. Third Edition. New York: McGraw-Hill Book Co., Inc. (1949).

2. Terman, F. E. Radio Engineering. Third Edition. New York: McGraw-Hill Book Co., Inc. (1947). 


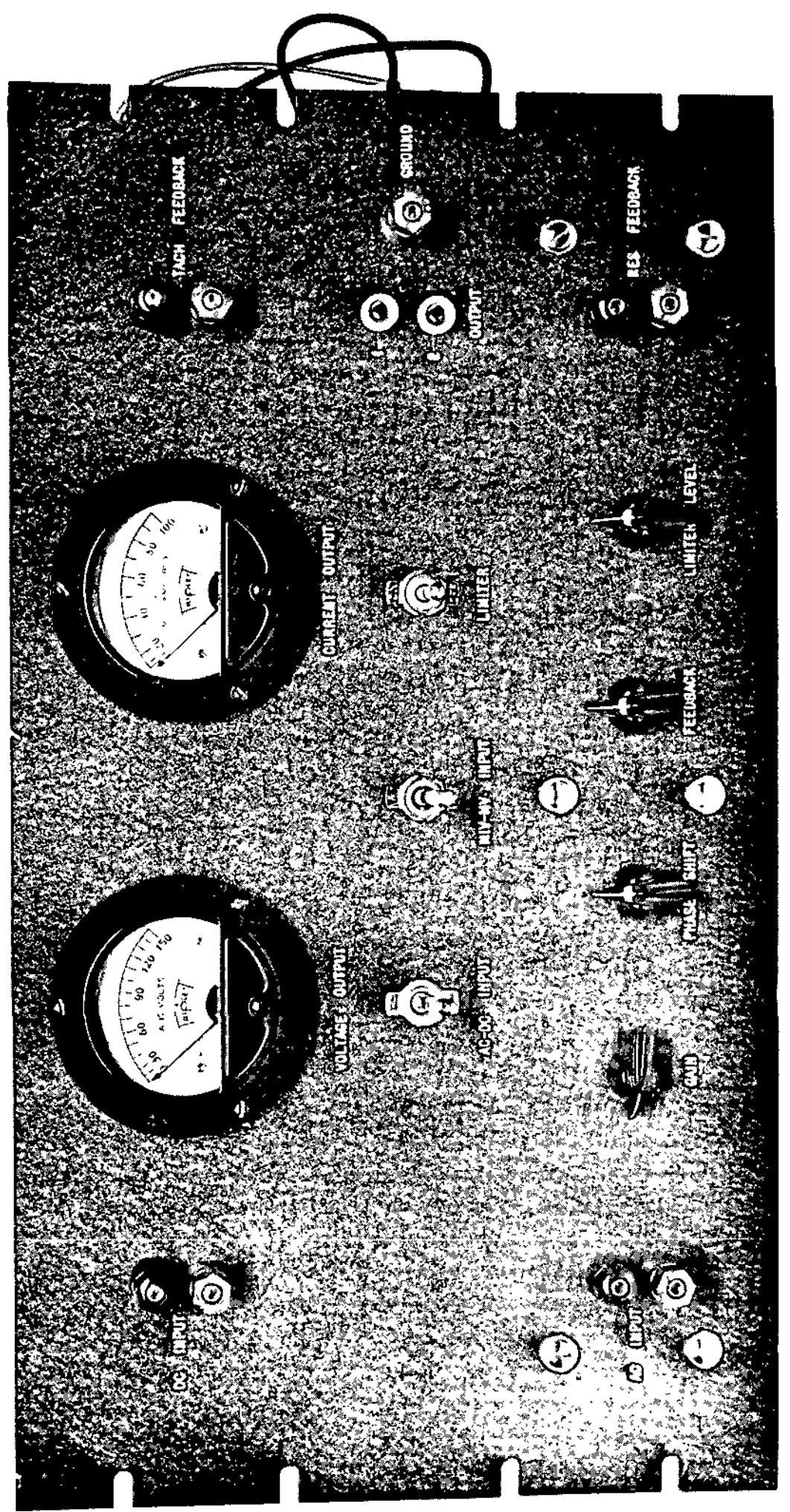

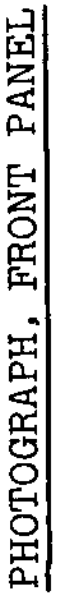




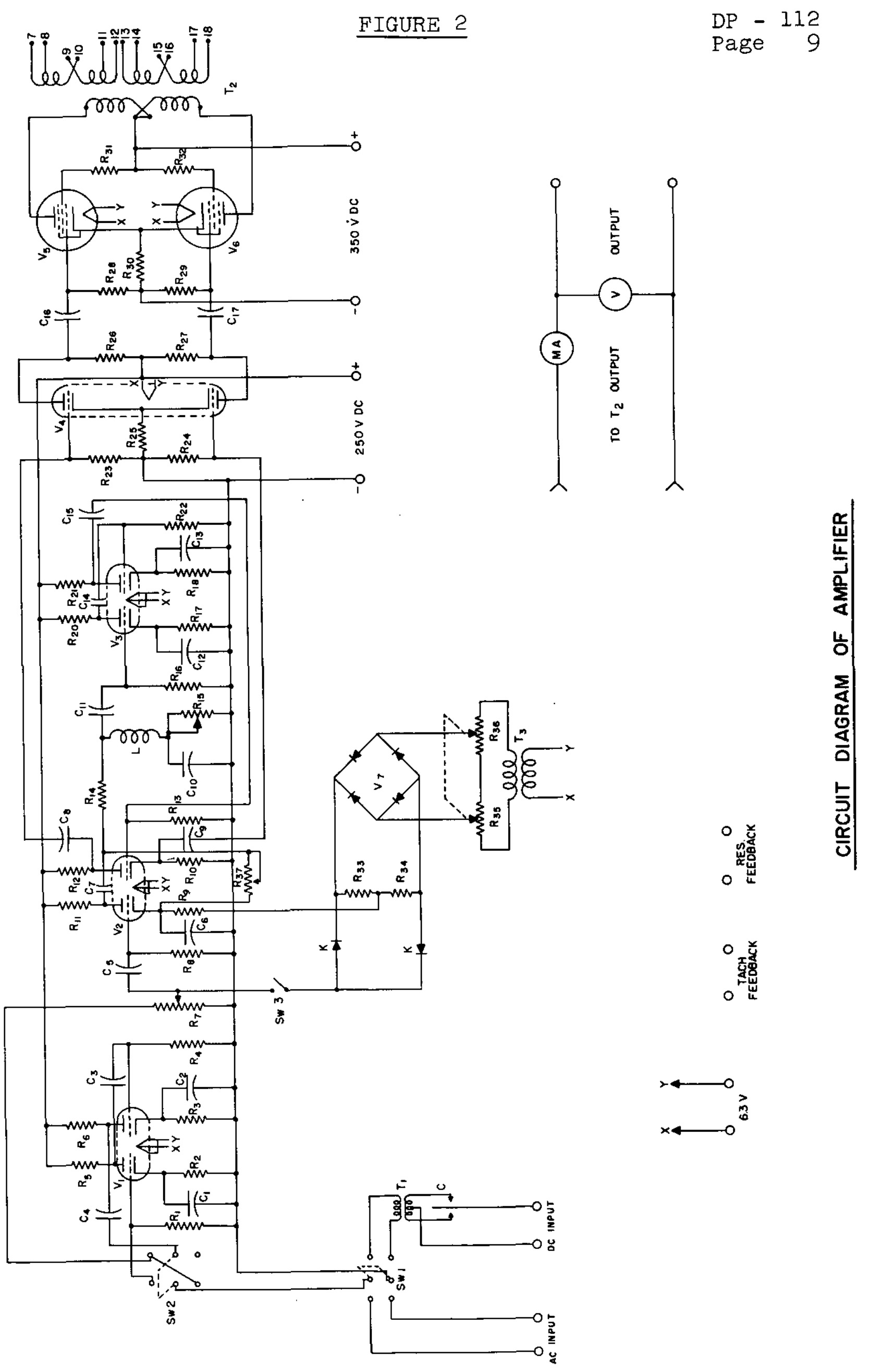


C-chopper - Brown Instrument Div. converter No. $354210-1$

Krdiodes - germanium diodes IN34A

- input \& feedback terminal posts - Superior Electric Co. DF 30 id 3 DF 30 BC

SWI - Carling No. 2 GM- 63 (DPDT center off)

SW2 - Cutler Hammer No. $8370 \mathrm{~K} 7$ (DPDT)

SW3 - Cutler Hammer No. 7501 K13 (SPST)

- power supply \& output jacks * H. H. Smith No. 219

- output power lead plugs - H. H. Smith No. 213

$\mathrm{V}$ - Triplett, model 331-5, 0-500 voltmeter

MA - Triplett, mode1 331-\$, 0-100 mililammeter

$\mathrm{T}_{1}$ - Brown Instrument Div. Input transformer No. 355567

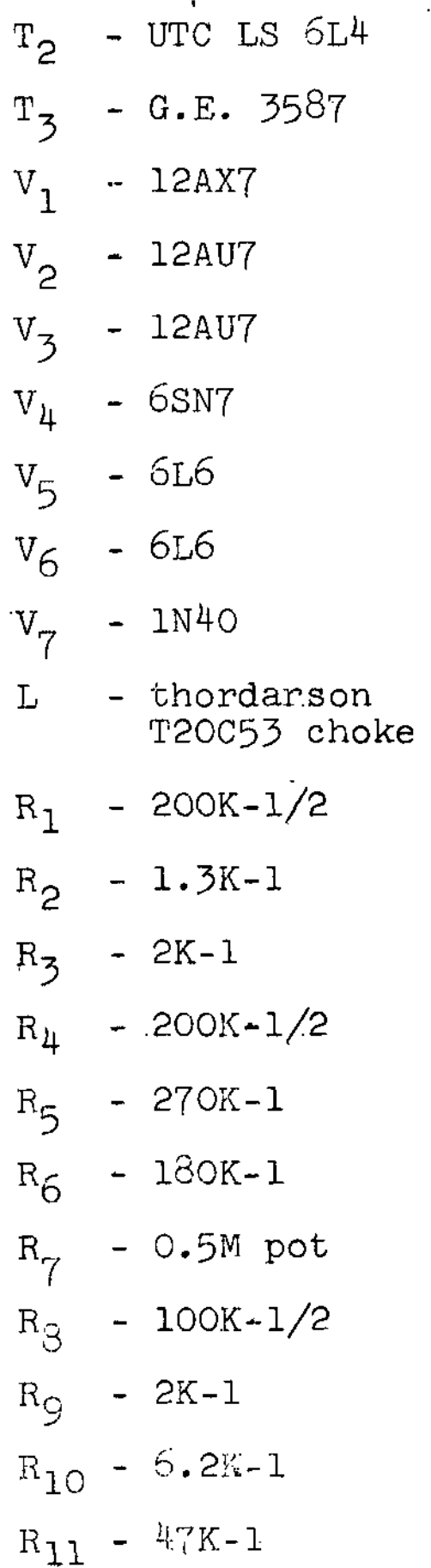

$\mathrm{R}_{12}-6.2 \mathrm{~K}-1$

$R_{13}-100 K-1 / 2$

$\mathrm{R}_{14}-200 \mathrm{~K}-1$

$R_{15}-250 \mathrm{~K}$ pot

$R_{16}-100 K=1 / 2$

$R_{17}-1.4 \mathrm{~K}-1$

$\mathrm{R}_{18}-1.4 \mathrm{~K}-1$

$R_{20}-47 \mathrm{~K}-2$

$\mathrm{R}_{21}$ - 200K-1

$R_{22}-200 K-1 / 2$

$R_{23}-270 \mathrm{~K}-1 / 2$

$\mathrm{R}_{24}-270 \mathrm{~K}-1 / 2$

$R_{25}-2.4 \mathrm{~K}-1$

$\mathrm{R}_{26} \cdot 75 \mathrm{~K}-1$

$\mathrm{R}_{27}-75 \mathrm{~K}-1$

$R_{28} \cdot 100 \mathrm{~K}-1 / 2$

$R_{29}-100 K-1 / 2$

$R_{30}-250-5$

$R_{31}-39 \mathrm{~K}-1$

$R_{32}-39 K-1$

$R_{33}-1 K-1$
$R_{34}-1 K-1$

$\mathrm{R}_{35}-10 \mathrm{~K}$ pot

$\mathrm{R}_{36}-10 \mathrm{~K}$ pot

$\mathrm{R}_{37}-1 . \mathrm{CM}$ pot

$\mathrm{C}_{1}-25 \mathrm{mfd} \cdot 25 \mathrm{~V}$

$\mathrm{C}_{2}-25 \mathrm{mfd} \cdot 25 \mathrm{~V}$

$\mathrm{C}_{3}-.47 \mathrm{mfd} \cdot 200 \mathrm{~V}$

$\mathrm{C}_{4}-.47 \mathrm{mfd} \cdot 200 \mathrm{~V}$

$\mathrm{C}_{5}-.47 \mathrm{mfd} \cdot 200 \mathrm{~V}$

$c_{6}-25 \mathrm{mfd} \cdot 25 \mathrm{~V}$

$\mathrm{C}_{7}-.47 \mathrm{mfd} \cdot 200 \mathrm{~V}$

$\mathrm{C}_{8}-.47 \mathrm{mfd} \cdot 200 \mathrm{~V}$

$\mathrm{C}_{9}-25 \mathrm{mfd} \cdot 200 \mathrm{~V}$

$\mathrm{C}_{10}-.147 \mathrm{mfd} \cdot 400 \mathrm{~V}$

$\mathrm{C}_{11}-.47 \mathrm{mfd} \cdot 400 \mathrm{~V}$

$\mathrm{C}_{12}-25 \mathrm{mfd} \cdot 25 \mathrm{~V}$

$\mathrm{C}_{13}-25 \mathrm{mfd} \cdot 25 \mathrm{~V}$

$\mathrm{C}_{14}-.47 \mathrm{mfd} \cdot 200 \mathrm{~V}$

$\mathrm{C}_{15}-.47 \mathrm{mfd} \cdot 2.00 \mathrm{~V}$

$\mathrm{C}_{16}-.47 \mathrm{mfd} \cdot 200 \mathrm{~V}$

$\mathrm{C}_{17}-.47 \mathrm{mfd} \cdot 200 \mathrm{~V}$ 


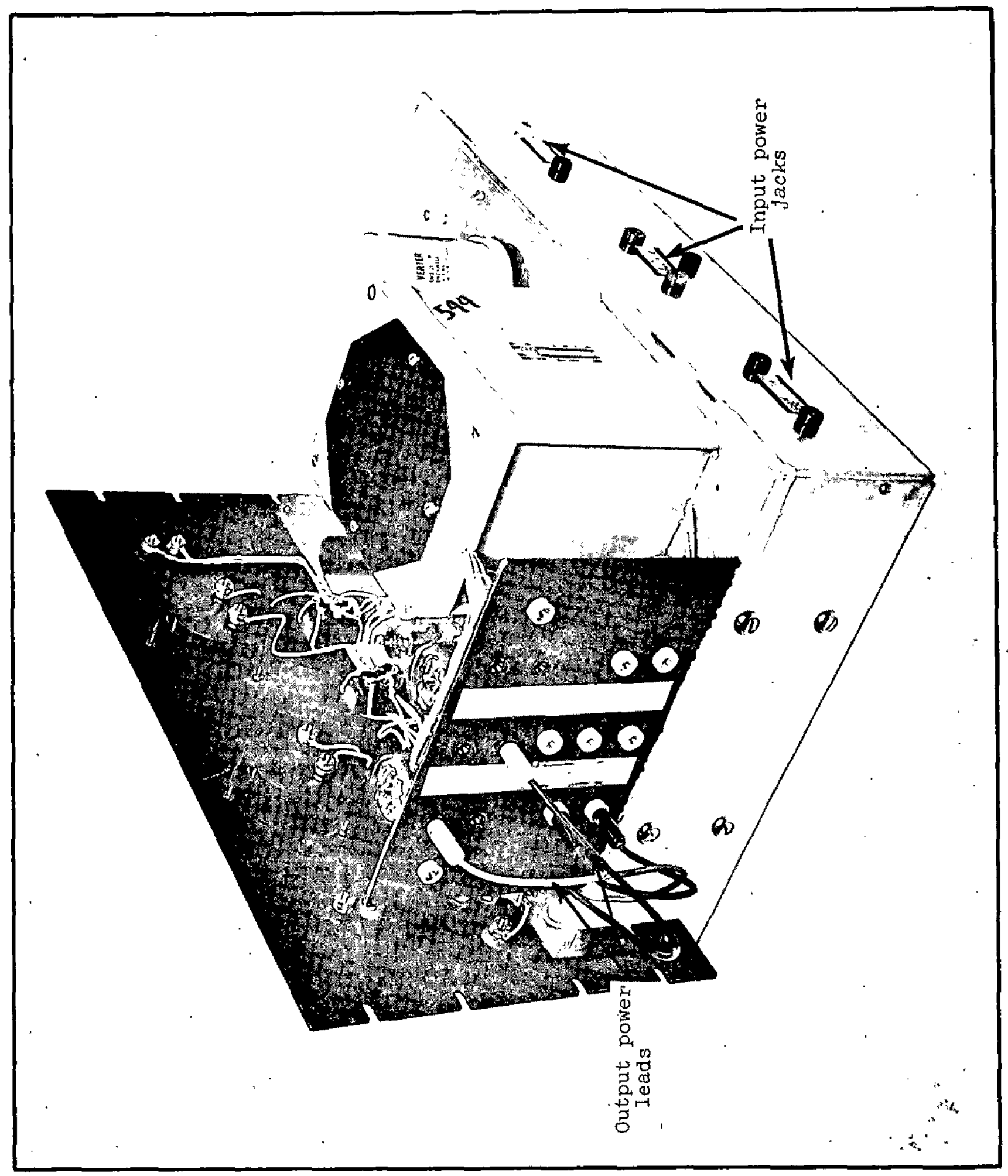

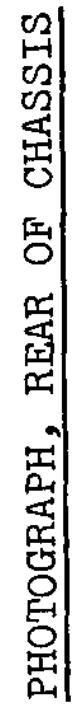

